\title{
1 Desert fish populations tolerate extreme salinity change to overcome hydrological constraints
}

$4 \quad$ Celia Schunter ${ }^{1}$, Lucrezia C. Bonzi ${ }^{2}$, Jessica Norstog $^{2}$, Jade Sourisse ${ }^{1}$, Michael L.

$5 \quad$ Berumen $^{2}$, Yoseline Angel ${ }^{3}$, Stephen D. Parkes ${ }^{3}$, Matthew F. McCabe ${ }^{3}$ and Timothy

$6 \quad \operatorname{Ravasi}^{4} *$

$8{ }^{1}$ Swire Institute of Marine Science, School of Biological Sciences, The University of

9 Hong Kong, Pokfulam, Hong Kong SAR

$10 \quad{ }^{2}$ Red Sea Research Center, Division of Biological and Environmental Sciences \&

11 Engineering, King Abdullah University of Science and Technology, Thuwal, Kingdom of

12 Saudi Arabia

$13{ }^{3}$ Water Desalination and Reuse Center, Division of Biological and Environmental

14 Sciences \& Engineering, King Abdullah University of Science and Technology, Thuwal,

15 Kingdom of Saudi Arabia

$16{ }^{4}$ Marine Climate Change Unit, Okinawa Institute of Science and Technology Graduate

17 University, 1919-1 Tancha, Onna-son, Okinawa 904-0495, Japan

18

19 *corresponding authors: Celia Schunter (celiaschunter@gmail.com) and Timothy Ravasi

20 (timothy.ravasi@oist.jp)

21 


\section{Abstract}

23 The unstable nature of freshwater ponds in arid landscapes represent a sizable challenge

24 for strictly aquatic organisms, such as fishes. Yet the Arabian Desert, bordering the

25 coastline of the Red Sea, plays host to a species very well adapted to such extreme

26 environments: the Arabian pupfish, Aphanius dispar. In this study, we estimated patterns

27 of hydrological connectivity; population structure and stable isotope for samples of $A$.

28 dispar living in small, isolated ponds of nearly-freshwater in the Arabian desert and

29 highly saline coastal lagoons along the Red Sea. The genomic and hydrological analyses

30 indicate that populations are largely separated by drainage origin, as fish from desert

31 ponds appear to be transported to coastal lagoons of the Red Sea along ephemeral river

32 systems arising from flash flood events. Further, our study indicates there is an ecological

33 change when being washed from pond environments to coastal waters, due to a

34 significant shift in muscle stable isotopes ratios between both groups. Considering that

35 the genetic breaks are mostly observed between drainage origin, this study suggests that

36 A. dispar can survive large changes in salinity and ecological regimes over small time-

37 scales. 


\section{Introduction}

40 Population dynamics are often defined and restricted by differences in environmental

41 conditions. A growing body of research shows that environmental gradients are often a

42 driver for selection, but also population structure, as adaptation to local conditions can

43 lead to selection of particular genotypes on either side of an ecological break (Wang \&

44 Bradburd, 2014). Differences in fitness and conditioning across such ecological gradients

45 can lead to restricted dispersal or even dispersal barriers, which in turn can significantly

46 shape the population structure at relatively small geographic scales (Sexton, Hangartner,

47 \& Hoffmann, 2014). This concept is tremendously important in evolutionary biology, as

48 ecological gradients have been suggested as one of the initial mechanisms of divergence

49 that can promote speciation of lineages (Doebeli \& Dieckmann, 2003).

51 A small number of species have the ability to traverse ecological barriers, even

52 significant dispersal barriers and eventually conquer some of the world's extreme

53 environments, via physiological and behavioural adaptations (Kelley et al., 2014; Moore,

54 Cooper, Biewener, \& Vasudevan, 2017). Among the most intriguing of these examples

55 are fishes that live in desert environments, as they inhabit highly isolated and often

56 ephemeral ponds in very arid landscapes. It is assumed that most of these species have

57 high phenotypic plasticity, as these fishes encounter ephemeral streams (Furness, 2016),

58 large temperature fluctuations (Bennett \& Beitinger, 1997), extreme changes in water

59 chemistry (Kavembe, Franchini, Irisarri, Machado-Schiaffino, \& Meyer, 2015) and high

60 spatiotemporal variability in water supply (Fisher, Gray, Grimm, \& Busch, 1982).

61 Among the main questions regarding these particular groups of fishes, the most intriguing 
62 is how such isolated populations continue to survive after an initial colonization event. It

63 is well known that isolation of populations can result in a slew of detrimental conditions,

64 such as loss of genetic variability, inbreeding depression or the accumulation of

65 deleterious mutations (Gaggiotti, 2003). Considering that population persistence and

66 long-term survival is largely influenced by genetic diversity (Bouzat, 2010), living in

67 isolated and highly restricted water bodies might threaten the persistence of desert fishes

68 over long time-scales.

70 Among the few fish groups that inhabit arid environments, Cyprinodontiformes exhibit

71 remarkable adaptations to extreme conditions. For example, the African turquoise

72 killifish (Nothobranchius furzeri) evolved an embryonic diapause, allowing fertilized

73 eggs to survive a dry period (Furness, 2016). Furthermore, killifish can also be found in

74 habitats with widely varying salinities and they are therefore categorized as euryhaline

75 (Wood \& Marshall, 1994). The genus Fundulus, for instance, displays a wide range of

76 osmotolerant physiologies (Whitehead, 2010), with F. heteroclitus being able to rapidly

77 acclimate to an osmotic shock by changing its transcriptional program and later

78 remodeling its tissues (Whitehead, Galvez, Zhang, Williams, \& Oleksiak, 2011). Despite

79 these remarkable adaptations, some Cyprinodontiformes occupy very restricted habitats.

80 For example, the Devils Hole pupfish (Cyprinodon diabolis) lives only in Devils Hole

81 (in the Amargosa Desert of Nevada) and it is described as occupying the smallest known

82 natural range (a single pool $<80 \mathrm{~m}^{2}$ ) for any vertebrate species (Martin, Crawford,

83 Turner, \& Simons, 2016). Indeed, many species of fish inhabiting such arid landscapes

84 are currently listed as endangered (Hopken, Douglas, \& Douglas, 2013; Van Haverbeke, 
85 Stone, Coggins, \& Pillow, 2013) and have been of conservation concern for decades

86 (Meffe \& Vrijenhoek, 1988).

87

88 The Arabian pupfish, Aphanius dispar (Cyprinodontidae), is present in the Middle East

89 with landlocked populations in countries such as Oman, Iran and Saudi Arabia (Al-

90 Kahem-Al-Balawi et al., 2008; Freyhof, 2014; Haas, 1982; Hrbek \& Meyer, 2003). This

91 species represents an interesting conundrum, as it has a large distribution range, but it

92 inhabits highly restricted ephemeral ponds with no permanent rivers around them.

93 Furthermore, from a pilot study we revealed that they are also present in coastal lagoons

94 of the Red Sea. Phylogenetic analyses of the genus suggest that this group has saltwater

95 ancestry, with the closing and drying of the Tethys Sea resulting in landlocked remnant

96 populations which likely then diverged due to the resultant strong ecological changes

97 (Hrbek \& Meyer, 2003).

98

99 In this study we explore suitable habitats for A.dispar to live in the desert as well as the

100 Red Sea coastline in Saudi Arabia and aim to understand the population connectivity of

101 this species. We investigate the environmental conditions and population structure of $A$.

102 dispar in the Arabian desert by employing a multi-disciplinary approach that combines

103 hydrological predictive mapping, population genomics, stable isotope analysis, as well as

104 chemical and physical analyses of water bodies. 


\section{Methods}

\section{Sample collection}

108 In order to acquire information on the presence of water ponds and streams in the Saudi

109 Arabian desert, extensive searches were performed using Google Earth, high-resolution

110 satellite data and through contacting local landowners and regional police. Subsequently,

111 a range of potential water ponds were identified and visited (see Figure 1). From a survey

112 of 28 locations, Aphanius dispar was detected at 11 sites and was collected using a $3 \mathrm{~m}$

113 wide seine net. Fish length was measured, and a piece of the dorsal fin was cut and

114 placed in $96 \%$ ethanol. Fish were then returned to the pond. Individuals with fins too

115 small for finclip collection were euthanized with a blow to the head, with the entire tail

116 preserved in ethanol. All procedures were performed in accordance with relevant

117 guidelines and regulations and were approved and completed with the ethics permit

118 15IBEC35_Ravasi from the Institutional Biosafety and BioEthics Committee (IBEC) of

119 the King Abdullah University of Science and Technology.

121 Stable isotopes

122 We employed two types of stable isotope measurements: fish muscle tissue and pond

123 water isotopes. Fish muscle tissue can give indications on the diet of the fish in the ponds

124 and the sea (Zanden \& Rasmussen, 2001). Water isotope analysis can indicate the

125 evaporative and flow processes of the water body. While these distinct isotopic

126 measurements have different applications, they both help to understand the biological and

127 hydrological connectivity of the ponds in the desert. Isotope ratios are reported relative to

128 their respective standards: 


$$
\text { 1) } \quad \delta=\left(\frac{R_{\text {sample }}}{R_{\text {standard }}}-1\right) \%
$$

130 where $R_{\text {sample }}$ and $\mathrm{R}_{\text {standard }}$ are the isotope ratios (heavier isotopologue to the more

131 abundant isotopologue) measured in the sample.

133 a) Water stable isotope analysis

134 Water samples from the six desert ponds were analyzed for isotope analysis at the King

135 Abdullah University of Science and Technology on a Picarro Wavelength Scanning

136 Cavity Ringdown Spectrometer (WSCRDS L115-I, Picarro Inc., Sunnyvale, CA, USA)

137 interfaced to a liquid autosampler (CTC HTC Pal liquid autosampler; LEAP

138 Technologies, Carrboro, NC, USA). $\delta^{2} \mathrm{H}$ and $\delta^{18} \mathrm{O}$ were measured and are isotope ratios

139 for ${ }^{2} \mathrm{H}^{1} \mathrm{H}^{16} \mathrm{O}$ and ${ }^{1} \mathrm{H}_{2}{ }^{18} \mathrm{O}$ isotopologues, respectively. Samples were referenced to the

140 VSMOW scale using laboratory working standards previously referenced to the

141 VSMOW2/ SLAP2 (Standard Light Antarctic Precipitation) standards. The $\delta^{2} \mathrm{H}$ and $\delta^{18} \mathrm{O}$

142 values of samples was determined using the two-point linear normalization method

143 described in Paul et al. (2007) (Paul et al., 2007), which calibrate sample isotope ratios

144 using the linear relationship between the true and measured isotope ratios of two working

145 standards that bracket the sample. Each measurement of standards and samples consisted

146 of 10 injections of which the last 4 were used to determine isotope ratios. Uncertainty for

147 the reported isotope values is determined by propagating the standard deviations $(1 \sigma)$ of

148 the last 4 injections from measurement of standards and samples.

150 b) Muscle tissue stable isotope preparation and analysis 
151 For each collection site, a subset of adult fish was sacrificed, and bodies were frozen with

152 dry ice in the field. In the lab, fish were thawed, and white muscle tissue was de-skinned,

153 descaled and dried for $24 \mathrm{~h}$ at $60{ }^{\circ} \mathrm{C}$. Samples were ground using a MP Bio FastPrep-24

154 instrument $(6.5 \mathrm{~m} / \mathrm{s}$ for 60 s until pulverized, repeated 1-4 times) and Lysing Matrix E 2

$155 \mathrm{~mL}$ tubes with $1 \times 4.0 \mathrm{~mm}$ ceramic sphere, $30 \pm 31.4 \mathrm{~mm}$ ceramic spheres. Tissues were

156 rinsed in $1 \mathrm{~mL}$ 2:1 chloroform-methanol solution and shaken vigorously for $30 \mathrm{~s}$ to

157 remove isotope differences due to a lipid content bias, as described by Ehrich et al.

158 (2011) (Ehrich et al., 2011). The solution was transferred to $1.5 \mathrm{~mL}$ Eppendorf tubes,

159 leaving the spheres behind. The samples were left to stand for 15 minutes at room

160 temperature, and then centrifuged for 10 minutes at 3,400 rpm. The supernatant was

161 discarded, and the chloroform-methanol rinse was repeated two additional times. Samples

162 were then dried in $1.5 \mathrm{~mL}$ Eppendorf tubes for $24 \mathrm{~h}$ at $60{ }^{\circ} \mathrm{C}$ and broken apart using a

163 scoopula. Approximately $1 \pm 0.2 \mathrm{mg}$ of sample was placed in tin capsules for solid

164 samples $(5 \times 9 \mathrm{~mm})$ for the Isotope Ratio Mass Spectrometry analysis (IRMS). ${ }^{13} \mathrm{C}$

165 and ${ }^{15} \mathrm{~N}$ isotopes were analyzed using a PDZ Europa ANCA-GSL elemental analyzer

166 interfaced to a PDZ Europa 20-20 isotope ratio mass spectrometer (Sercon Ltd.,

167 Cheshire, UK) at the Stable Isotope Facility at the University of California, Davis.

168 Briefly, samples were combusted at $1000^{\circ} \mathrm{C}$ with chromium oxide and silvered copper

169 oxide, with a subsequent oxides removal in a reduction reactor. $\mathrm{N}_{2}$ and $\mathrm{CO}_{2}$ were

170 separated on a Carbosieve GC column $\left(65^{\circ} \mathrm{C}, 65 \mathrm{~mL} / \mathrm{min}\right)$ before entering the IRMS.

171 Samples were interspersed with replicates of two laboratory standards and isotope ratio

172 delta values were measured relative to the international standards VPDB (Vienna

173 PeeDee Belemnite) and Air for carbon and nitrogen, respectively (Sharp, 2007). 
174 Statistical analyses for tissue stable isotopes were carried out using $\mathrm{R}$ ( $\mathrm{R}$ version 3.4.0,

175 2017-04-21). Data were checked for normality with the Shapiro-Wilk test and for

176 homogenous variance with the Fligner-Killeen test and considered significant at $p<0.05$.

177 The correlation between $\delta^{13} \mathrm{C}$ and $\delta^{15} \mathrm{~N}$ was tested with a Spearman's correlation, as well

178 as the allometric effect of size on isotope contents. Since data did not satisfy conditions

179 for the use of parametric statistics, a two-way non-parametric ANCOVA in the sm

180 package (Bowman \& Azzalini, 2014) was used to test for differences in $\delta^{13} \mathrm{C}$ and $\delta^{15} \mathrm{~N}$

181 among sites, with fish size as the covariate. Sampling sites of $A$. dispar were split into

182 two water type groups (Desert Pond and Sea Water), as well as in four different clusters

183 (determined through genetic and hydrological analysis, stated below), depending on the

184 drainage basin they belong to (from north to south: Cluster 1 = DP1, DP2, SW1, SW2;

185 Cluster 2 = DP3, SW3; Cluster 3 = DP4, SW4; Cluster 4 = DP5, DP6, SW5). Differences

186 in fish muscle isotopic signatures between different desert pond were also evaluated.

187 Muscle mean content in $\delta^{13} \mathrm{C}$ and $\delta^{15} \mathrm{~N}$ and standard deviation for the different sites (n:

$188 \mathrm{DP} 3=11, \mathrm{DP} 4=11$, all others $=12$ ) were calculated and visualized in R.

190 Water parameters and samples

191 To quantify the water chemistry of the desert ponds and better understand the

192 environmental conditions of the fish habitat, we took in situ measurements as well as

193 collected water samples for later analyses. A portable Ocean Seven 305 Plus CTD

194 (Idronaut) was used to measure temperature, pressure, conductivity, salinity, percent

195 oxygen saturation, parts per million of $\mathrm{O}_{2}$ and $\mathrm{pH}$ on site. The CTD sonde was submersed

196 at a depth of approximately $30 \mathrm{~cm}$ and left to acclimate for one minute. Five minutes of 
197 measurements were taken at a sampling rate of 5 seconds, with the total of 60 data points

198 averaged to provide a single value for each parameter per site (referred to as "average

199 temperature"). Water samples at each site were collected in $500 \mathrm{ml}$ HDPC containers,

200 either filled only with water for isotope and water analysis, or with $2 \mathrm{ml}$ of $5 \%$ nitric acid

201 for preservation for chemical water analysis. Water samples were analyzed using Ion

202 Chromotography. Seawater samples (sites SW1 - SW5) were diluted x10 and filtered

203 using Dionex OnGuard II Ba/Ag/H 2.5 cc cartridges to remove $\mathrm{SO}_{4}{ }^{2-}$ and $\mathrm{Cl}^{-}$. Standards

204 and water samples were transferred to Autoselect Polyvial $10 \mathrm{~mL}$ vials and covered with

205 septa and caps. Samples were run on Dionex ICS-3000 with the Chromeleon

206 Chromatography Management System (version 6.7) program and using an autosampler.

207 Photometric analysis was performed on water samples to measure for chlorides, sulphates

208 and silica. Standards were run accordingly (chlorides: 0 ppm, 20 ppm, 200 ppm;

209 sulphates: 0, 30 and $100 \mathrm{ppm}$; silica: 0, 100 and $500 \mathrm{ppb}$ ). Water samples were

210 transferred to cuvettes and loaded into an Aquakem 250 (Thermo Scientific) for analysis.

211 For samples that were outside of standard ranges, samples were diluted appropriately (see

212 Supplementary materials) and re-run.

214 Streamflow mapping

215 To establish the hydrological connectivity from the desert highlands to the Red Sea

216 coastline (and the resultant possible genetic links between the locations where pupfish

217 were present), we needed to determine the predominant flow direction at each cell of an

218 underlying topographic model. The ArcGIS-based hydrology toolset was used for the

219 extraction and analysis of watersheds and streamflow, using the Advanced Spaceborne 
220 Thermal Emission and Reflection Radiometer (ASTER) Global Digital Elevation Model

221 (ASTGTM, JPL 2009) to provide a topographic description of the region. Raw ASTER

222 data, distributed by NASA as GeoTIFF files, have a $30 \mathrm{~m}$ spatial resolution and are

223 referenced to the WGS84 coordinate system. Supplementary Figure 1 shows the flow

224 process of delineating watershed boundaries and stream networks from a digital elevation

225 model (DEM). To ensure that any water "flow" can move from one cell to any adjacent

226 cell, a depressionless DEM was obtained by filling any localized "sinks" that might have

227 formed as an artefact of the interpolation process. From this, the natural flow direction (as

228 dictated by the direction of steepest descent) and the flow accumulation per cell (i.e. the

229 number of upstream cells "draining" to that particular cell) can then be calculated. Only

230 those cells with a high accumulation threshold (>1000 contributing cells) are considered

231 to represent a dominant flow path. A streamline can be produced by connecting these

232 cells. Watershed boundaries are delineated automatically based on the natural water

233 divides, which follow the highest elevations in the DEM. Using Google Earth imagery

234 (Google Earth 7.1.2.2041; December 31, 2016) as an underlying base map, we can

235 determine the potential connectivity routes for fish by following delineated streamlines

236 from the highest sampled locations on the mountains, to the lowest points near the

237 shoreline. A visual interrogation of satellite images allowed elements such as dams,

238 bridges, culverts and agricultural regions to be identified and to manually edit segments

239 along the streamlines.

240

241 DNA extractions and Restriction Site Associated DNA Sequencing (RAD-Seq) 
242 To understand the genetic population structure and genetic connectivity of $A$. dispar we

243 used $5 \mathrm{~mm}$ pieces of fin clip from each individual sample for 28-29 individuals per site

244 (at 11 sites) to extract DNA with 96-well DNA extraction kits from Qiagen (DNeasy 96

245 Blood and Tissue Kit) or Macherey-Nagel (NucleoSpin 96 Tissue). The manufacturer

246 protocols were followed with a deviation of 8-10 hours of lysis and elution in $50 \mu 1 \mathrm{H}_{2} 0$.

247 Concentrations were measured with a Qubit 2.0 fluorometer with a dsDNA High

248 Sensitivity reagent kit. We used a modified double digest (ddRad) protocol (Peterson,

249 Weber, Kay, Fisher, \& Hoekstra, 2012). Briefly, DNA was digested using SphI High

250 Fidelity and MluCI High Fidelity enzymes with the appropriate CutSmart Buffer (New

251 England Biolabs) and cleaned with AMPURE XP beads. Adapters were ligated to $100 \mathrm{ng}$

252 of digested DNA with a combination of sixteen adapters and eleven indices to uniquely

253 identify individual samples out of 80 multiplexed samples in one sequencing lane. Pools

254 were created from equally concentrated and cleaned samples and size selected in a

255 BluePippin (Sage Science) with $2 \%$ Gel Cassettes to a size of 300bp. We used a KAPA

256 Hifi Ready Mix for the PCR amplification with ten PCR cycles and temperatures

257 according to the manufacturer. Samples were run on a bioanalyzer (Agilent) and a qPCR

258 (7900 HT Fast Real Time PCR system, ABI) was used to quantify and combine all 80

259 samples within one library at equimolar concentration. Four libraries were then

260 sequenced paired-end on an Illumina Hiseq2000 to a length of 100bp at the KAUST

261 Bioscience Core Lab facility.

262

$263 \quad R A D-S e q$ data processing 
264 Raw sequence fastq files were de-multiplexed for each lane of Illumina using

265 process_radtags in the software STACKS 1.40 (Catchen, Hohenlohe, Bassham, Amores,

266 \& Cresko, 2013). All sequences were quality trimmed with Trimmomatic 0.33 (Bolger,

267 Lohse, \& Usadel, 2014) with a Phred score quality cutoff of 30. Individuals with less than

268300,000 remaining first read sequences (from paired end reads) were removed from the

269 analysis. Due to the lack of a reference genome for this species, we ran the quality

270 trimmed first read files through the denovo_map perl script in STACKS. The final

271 optimized parameters were set to a conservative number of mismatches allowed (-n 2 and

272 -M 2), a minimum number of identical reads to form a stack was three and SNP calling

273 was performed with an upper bound error rate of 0.05 (--bound_high 0.05). After the

274 putative SNP detection, the function populations was run to select putative SNPs meeting

275 several criteria. The variant had to have a minimum read number of $10(-\mathrm{m} 10)$, be

276 present in at least seven of the eleven locations (-p 7) and in more than 20 individuals per

277 locations (-r 0.72). A minimum allele frequency filter of 0.05 was applied and we chose

278 to use one randomly putative SNP from each stack. The resulting vcf file was converted

279 into different input file formats for further analysis using PGDSPIDER (Lischer \&

280 Excoffier, 2012). To avoid a bias due to duplicated sequences across the genome,

281 putative SNPs were discarded if heterozygosity was higher than 0.5 (calculated with

282 vcftools, following (Danecek et al., 2011) and if the mean read depth was a median

283 absolute deviation away from the median depth (Seeb et al., 2014). Hardy-Weinberg

284 exact tests were performed in Genepop version 4.6 (Rousset, 2008) and putative SNPs

285 were removed if there was a significant deviation in more than four of the eleven 
286 locations for which tests could be performed. All SNPs that did not pass the criteria were

287 blacklisted in populations and removed from further analysis.

289 Population genetics and clustering analyses

290 Population genetics metrics such as average allele number, private alleles, inbreeding

291 coefficient and locus and pair-wise $\mathrm{F}_{\mathrm{ST}}$ were obtained for the set of filtered final SNPs

292 with populations. VCFtools v0.1.13 was used to look at minor allele frequencies, Hardy-

293 Weinberg equilibrium and locus and population heterozygosities (Danecek et al., 2011).

294 Pairwise AMOVA $\mathrm{F}_{\mathrm{ST}}$ values for population differentiation measures and significance

$295(\mathrm{p}<0.05)$ were obtained in GenoDive V2.0b27 using 10,000 permutations as well as the

296 pairwise kinship coefficient $\mathrm{r}$ (Meirmans \& Van Tienderen, 2004). Effective population

297 sizes were calculated in NeEstimator using the linkage disequilibrium method including

298 all final selected SNP loci (Do et al., 2014). Here we present the results of the largest

299 harmonic mean sample size per population.

300 To evaluate genetic structure among all sampled individuals, we performed a principal

301 component analysis (PCA) as well as Bayesian clustering analysis. The PCA was

302 computed in the adegenet package v. 2.0.1 in R (Jombart, 2008). We represent the

303 eigenvalues of the analysis revealing the variance of each principal component and a

304 scatterplot summarizing the genetic diversity including the center ellipses per sampling

305 location. Clustering analysis was performed in Structure v.2.3.4 (Pritchard, Stephens, \&

306 Donnelly, 2000) under the admixture model with a 10\% burn-in period and 500,000

307 iterations of Markov Chain Monte Carlo (MCMC), which creates a probability

308 distribution and allows for the evaluation of the likeliness of different numbers of clusters 
309 (K) within the dataset. Ten replicates were run for each putative number of clusters (K)

310 with $\mathrm{K}$ ranging from 1 to 11 . The results were then passed through STRUCTURE

311 HARVESTER v0.6.94 (Earl \& vonHoldt, 2012) to apply the ad hoc statistic delta K

312 proposed by Evanno and coauthors (2005). Resulting individual and population files

313 were used in CLUMPP v1.1 (Jakobsson \& Rosenberg, 2007) and DISTRUCT v1.1

314 (Rosenberg, 2003) to combine all STRUCTURE runs and visualize the results.

316 Loci under selection

317 As A. dispar individuals were found in very different habitat types (from desert ponds to

318 the highly saline waters of the Red Sea) we tested for possible selection in any of the

319 analyzed loci possibly indicating adaptive processes to the environmental conditions. For

320 this we re-ran the populations program with the same whitelist of 5,955 loci selecting

321 specific locations. First, all locations were used by defining all desert pond locations as

322 one population and all seawater location as another one, in order to evaluate global

323 selection between desert and seawater habitats. However, adaptive processes might differ

324 for the different desert ponds and we therefore sub-selected locations. We evaluate

325 adaptive loci for DP1 \& DP2 against SW1 \& SW2, DP3 vs. SW3, DP4 vs. SW4, and

326 DP5 \& DP6 against SW5. Each resulting vef files was format converted with PGDSpider

327 2.0.0.2 (Lischer \& Excoffier, 2012). For outlier loci detection we used a Bayesian

328 approach incorporated in Bayescan v2.1 (Foll \& Gaggiotti, 2008). Briefly, posterior odds

329 of a locus being under selection are obtained with MCMC with the help of the proportion

330 of loci exhibiting large $\mathrm{F}_{\mathrm{ST}}$ in comparison to other loci. To further minimize the number

331 of false positives, the prior odds was increased to 100 (-pr_odds 100). Outlier loci were 
bioRxiv preprint doi: https://doi.org/10.1101/2021.05.14.444120; this version posted May 16, 2021. The copyright holder for this preprint (which

was not certified by peer review) is the author/funder, who has granted bioRxiv a license to display the preprint in perpetuity. It is made available under aCC-BY-NC-ND 4.0 International license.

332 then visualized and selected in R after applying a False Discovery Rate (FDR) of 0.05.

333 Sequence reads for resulting putative loci under selection were then blasted against the

334 NCBI nr database (blastn) and successful blast hits are presented if the evalue was below

$3351 \mathrm{e}^{-5}$.

336 


\section{Results}

338 Pupfish locations, collection and pond properties

339 Due to the lack of previous knowledge on the locations of the Arabian pupfish

340 populations in western Saudi Arabia, we sampled 28 sites, of which only eleven had

341 pupfish present (Figure 1). 12 Red Sea coastline sites and 16 inland enclosed ponds or

342 streams were visited (Table $1 \&$ Supplementary Table 1); 6 inland sites and 5 seawater

343 sites had Aphanius dispar specimen. For two inland ponds, no sonde measurements could

344 be obtained due to complications transporting the CTD (conductivity, temperature and

345 depth) sonde into the steep canyons. Five ponds contained freshwater with a salinity

346 upper maximum threshold of $0.5 \mathrm{ppt}$, whereas salinity in the other nine measured ponds

347 ranged from 0.54 to 1.45 ppt. Most of the ponds therefore consisted of brackish water.

348 Aphanius dispar was only found in ponds with salinities higher than 0.74 ppt. pH ranged

349 between 7.71 to 9.41 across all sites, with the majority exhibiting a pH between 8 and 9 .

350 The average temperature in the inland ponds was $28.9^{\circ} \mathrm{C}( \pm 4.9 \mathrm{SE})$, while in the Red Sea

351 sites it was $21.9^{\circ} \mathrm{C}( \pm 4.17 \mathrm{SE})$. Sampling of fish was performed during the late boreal

352 autumn and early winter months (i.e., November-January), hence during the period of

353 lowest temperature of the year. The highest average water temperature, $38.4{ }^{\circ} \mathrm{C}$, was

354 observed at the Al Lith hot spring. At this site, pupfish live in higher temperatures in

355 comparison to all other sites, as well as with larger water content of silica (80,470 ppb).

356 These results illustrate the wide range of environments which pupfish populations are

357 able to exploit along the Red Sea coast.

359 Water stable isotopes 
360 To further understand environmental conditions of the six inland ponds inhabited by $A$.

361 dispar, water samples were collected, and their stable oxygen and hydrogen isotopes

362 measured (Supplementary Table 1). This can aid in understanding the source of the water

363 in the desert pond and if evaporation occurs comparatively, which can indicate water

364 flow or standing waters. A strong linear relationship between the $\delta^{2} \mathrm{H}$ and $\delta^{18} \mathrm{O}$ of these

365 samples was observed, with a slope of 4.83. Supplementary Figure 2 shows the linear

366 regression of measurements, with data exhibiting a low slope compared to the Global

367 Meteoric Water Line (GMWL). The relatively low slope indicates samples were subject

368 to significant evaporative enrichment (Gat, 1996; Gibson, Birks, \& Edwards, 2008;

369 Gibson \& Reid, 2014). The linear relationship between $\delta^{2} \mathrm{H}$ and $\delta^{18} \mathrm{O}$ across all samples

370 indicates a common water source derived from a single recharge event, with variability

371 between samples caused by the degree of evaporative enrichment for each water pool.

372 This is consistent with observations made at each site, with DP1 and DP2 being the two

373 most stagnant ponds with the least oxygen and greatest $\delta^{2} \mathrm{H}$ and $\delta^{18} \mathrm{O}$ isotopic enrichment

374 (Table 1).

375

376 Streamflow mapping

377 The overall topography of the study region is a mountainous inland region that is 378 bounded to the east by the Arabian shield, and which drains westward to a flatter desert 379 terrain towards the Red Sea coastline. In order to understand the hydrology of the area 380 and the exact hydrological constraints for the Arabian pupfish we created streamflow 381 maps for each sample location derived from a satellite-based digital elevation model. 382 Using the derived stream networks, a total of 6 different migration pathways were 
383 identified within the study area (Figure $2 \&$ Supplementary Table 4). Figure 2 illustrates

384 the digital elevation model (DEM) based hydrological connectivity as streamlines

385 flowing from each of the desert site locations where pupfish were present. We find that

386 during periods of occasionally intense or sustained rainfall, the desert ponds may become

387 hydrologically connected to their downstream saltwater location through tributary and

388 main stem water flow. Four distinct areas of potential hydrological connectivity can be

389 determined from Figure 2. In the northern portion of our study region, water from DP1

390 and DP2 are hydrologically linked via defined streamlines to SW1. SW2 serves as a

391 regional seawater sample pair for SW1, as it is separated by a distance of approximately

$39240 \mathrm{~km}$. Further south, there is delineated connectivity between DP3 and SW3, as well as

393 between DP4 and SW4. In the southernmost part of the sampling area, DP6 has a

394 tributary stream that connects with SW5, while DP5 has a separate watercourse to the

395 sea. It is important to note that these streamlines do not represent active flow paths, as

396 Saudi Arabia has no permanent rivers. Instead, the streamlines describe either

397 permanently or intermittently dry riverbeds, defined as a function of the topography, with

398 ephemeral flows only occurring in cases of sufficient rainfall.

$400 \quad$ RAD-sequencing

401 In order to verify the potential hydrological connectivity for the Arabian pupfish, we use

402 Single Nucleotide Polymorphism (SNPs) genetic markers to evaluate the genetic

403 population connectivity of Aphanius dispar. For this we genotyped between 28 and 30

404 individuals per site for the eleven A. dispar locations by means of RAD-sequencing

405 (Table $2 \&$ Supplementary Table 2). Over 2 million sequence reads were obtained on 
406 average for each individual. Six samples were removed from further analysis as they had

407 fewer than 300,000 reads after demultiplexing and quality trimming, resulting in 27 to 30

408 individual samples per location. The total final sample number was 314 individuals for 11

409 sites (five saltwater and six desert pond localities) (Figure 1). A total of 690,084 putative

410 single nucleotide polymorphisms (SNPs) were obtained with STACKS (Catchen et al.,

411 2013), which were stringently filtered to a final 5,955 SNP loci. The average depth of

412 coverage for these loci was $48 \mathrm{x}$, with a minimum of $24 \mathrm{x}$ and an average minor allele

413 frequency of 0.21 (Supplementary Figures 4 \& 5).

415 Population genomics

416 The number of alleles across the 5,955 SNP loci ranged from 1.3 to 1.8 for the different

417 locations (Table 2). Heterozygosity revealed lower levels for desert ponds and

418 particularly for desert pond DP4 the lowest heterozygosity among all locations, while

419 also having a negative inbreeding coefficient ( $\left.\mathrm{F}_{\mathrm{IS}}\right)$. DP4 also exhibited the most private

420 alleles (27) followed by DP1 with 15 and SW2 with 13. Three seawater locations SW3-

421 SW5 had no private alleles. Pairwise genetic distance between populations $\left(\mathrm{F}_{\mathrm{ST}}\right)$ was

422 highest for DP4, with almost all values above 0.2 and the closest genetic distance with

423 SW4 (Figure 3). The lowest value (0) was observed for DP1 and DP2. Interestingly, most

424 DP locations showed higher $\mathrm{F}_{\mathrm{ST}}$ values when compared to other DP localities than with

425 SW locations, indicating a clear disconnection between desert pond sites. Exceptions to

426 this include DP5 and DP6, with an $\mathrm{F}_{\mathrm{ST}}$ value of 0.048. Pairwise $\mathrm{F}_{\mathrm{ST}}$ comparisons between

427 seawater localities ranged between 0.005 to a maximum of 0.105 (SW2 vs SW5). 
428 Effective population size ranged between a very low 51 in DP4 to nearly 6,000 in SW2

429 (Table 2). DP3 was the only other site with an effective size below 1,000.

430 Bayesian clustering and ad hoc testing allowed for the approximation of the most likely

431 number of clusters within the analyzed samples. The most probable cluster numbers were

4322 or 8 , but delta $\mathrm{K}$ ad hoc testing also showed a peak at K=4 (Supplementary Figure 6).

$433 \mathrm{~K}=2$ divides the northern localities (DP1, DP1\& SW1, SW2) from the southern sites,

434 with DP3 and SW3 being an admixed group. When considering four different genetic

435 units in our data set, a division from north to south is found, combining desert ponds and

436 seawater locations together into clusters (Figure 4). In this scenario, DP4 stands out as the

437 only locality with its own cluster. SW4 in turn seems to have the most genetically

438 admixed individuals of all locations. By increasing the cluster number to 8 , a further

439 subdivision in the northern part can be found, separating the two desert ponds from the

440 seawater locations (DP1 \& DP2 and SW1 and SW2). Here SW4 and SW5, the two

441 furthest southern seawater sites, appear to share some unique traits (represented by the

442 yellow cluster in Figure 4b), which are not shared with the southern desert ponds.

443

$444 \quad$ Hydrological and genetic connectivity

445 The population clustering in the principal component analysis revealed a break between

446 the four northern locations (SW1, SW2, DP1 and DP2) and the seven southern ones,

447 regardless of them being desert ponds or seawater sites (Figure 5a). The two desert

448 ponds DP1 and DP2 closely clustered together as well as the two seawater locations

449 (SW1 and SW2), with some distance between the two different environments. This 
450 disjunction, however, is not seen through hydrological mapping, as DP1 \& DP2 have

451 hydrological connectivity to SW1.

453 Since annual rainfall volume tends to increase from the north towards the south (i.e.

454 heavier and more frequent rainfalls towards the south (El Kenawy \& McCabe, 2016)), the

455 likelihood of genetic connectivity might also be expected to increase amongst the

456 southern sample sites. In fact, with the exception of DP4, a decrease in genetic distance

457 between locations from the northern area to the south one was found. Moreover, in the

458 southern parts of the study area, less genetic distance was found between desert pond and

459 the nearest seawater location (DP3 with DP4; DP4 with SW4 as well as DP5, DP6 and

460 SW5). This is in accordance with the hydrological map, where water flow is possible

461 from the desert pond sites to the respective wadi (ephemeral river systems appearing

462 during intense rain periods) outlets in the Red Sea. It is not unusual for significant flow

463 events or even flash-floods to occur on an annual, or multi-annual basis (Deng et al.,

464 2015), potentially providing the mechanism behind the observed genetic connectivity

465 within the population clusters. When evaluating the third principal component, large

466 genetic distance between DP4 and most other locations becomes apparent (Figure 5b).

Putative environmental selection

469 Possible selective processes to different environmental condition were evaluated using an

$470 \quad F_{\text {ST }}$ outlier approach. All desert pond locations were grouped together and compared with

471 all seawater locations, resulting in five outlier loci (Table 3). Based on the population

472 genetic analyses, subsets of desert ponds and genetically close seawater locations were 
473 evaluated separately as well. In the northern part, the analysis included two desert ponds

474 (Desert Pond (DP)1 \& DP2) and two seawater locations together (Sea Water (SW) 1 \&

475 SW2), and resulted in one outlier loci which was also detected during an analysis that

476 included all sites. The comparison of DP4 and SW4 resulted also in one outlier.

477 Comparing DP3 and SW3 recovered one locus only, whereas the three southernmost

478 locations exhibited ten outliers. There is no common overlapping outlier loci detected

479 among the independent salt versus desert pond comparisons. Out of the 21 unique outliers

480 detected in the different subsets of data, 10 could be successfully identified by homology

481 using BLAST, and include several genes involved in immune response and ion channels.

482 The list of NCBI description and accession number can be found in Table 3.

483

$484 \quad$ Muscle tissue stable isotopes

485 To investigate further into differences between locations and environmental influence on

486 A. dispar we analyzed nitrogen and carbon stable isotopes in fish white muscle tissues.

487 These analyses revealed a clear separation between pupfish from inland ponds and

488 saltwater Red Sea habitats (Figure 6). The mean values for $\delta^{13} \mathrm{C}$ and $\delta^{15} \mathrm{~N}$ for desert pond

489 fish (DP) ranged between $-21.49 \%$ and $-26.28 \%$ (SD: $2.39 \%$ to $3.82 \% 0$ ) and $12.63 \%$ and

$49021.03 \%$ (SD: $1.62 \%$ o to $4.31 \%$ ), respectively. Saltwater fish (SW) isotope mean values

491 ranged between $-6.13 \%$ and $-11.62 \%$ for $\delta^{13} \mathrm{C}$ (SD: $1.21 \%$ o to $1.58 \%$ ) and between

$4925.92 \%$ and $10.90 \%$ or for $\delta^{15} \mathrm{~N}$ (SD: $0.61 \%$ o to $1.25 \%$ ). Overall, DP sites were more

493 depleted in $\delta^{13} \mathrm{C}$ than SW, but had the highest values of $\delta^{15} \mathrm{~N}$. The isotopic signatures of

$494 \delta^{13} \mathrm{C}$ and $\delta^{15} \mathrm{~N}$ correlated significantly $(\mathrm{p}<0.0001, \rho=-0.85)$. While gender did not result

495 in a significant covariate ( $\mathrm{p}>0.05$ ), fish length was significantly correlated with both 
$496 \delta^{13} \mathrm{C}(\mathrm{p}<0.0001, \rho=-0.39)$ and $\delta^{15} \mathrm{~N}(\mathrm{p}=0.0002, \rho=0.32)$ values. Our data did not

497 pass the normality test (Shapiro-Wilk test, $\mathrm{p}<0.0001$ ) nor the homoscedasticity test

498 (Fligner-Killeen test, $\left.\delta^{13} \mathrm{C} p=0.0003 ; \delta^{15} \mathrm{~N} p<0.0001\right)$. For these reasons, to test the

499 differences between DP and SW isotope contents correcting for fish size, a nonparametric

500 ANCOVA was used. There was a strong water type effect on both $\delta^{13} \mathrm{C}$ and $\delta^{15} \mathrm{~N}$ fish

501 content $(\mathrm{p}<0.0001)$. When testing the differences within clusters (cluster $1: \delta^{13} \mathrm{C} \mathrm{p}=$

$5020.0037, \delta^{15} \mathrm{~N} p=0.0039$; cluster $2: \delta^{13} \mathrm{C} \mathrm{p}=0.0385, \delta^{15} \mathrm{~N} \mathrm{p}=0.0352$; cluster $3: \delta^{13} \mathrm{C} \mathrm{p}$

$503=0.0370 ; \delta^{15} \mathrm{~N} \mathrm{p}=0.0350$; cluster $\left.4: \delta^{13} \mathrm{C} \mathrm{p}=0.0121 ; \delta^{15} \mathrm{~N} \mathrm{p}=0.0141\right)$, the same result

504 was obtained, with a strong segregation between saltwater and desert pond samples,

505 irrespective of geographic proximity. When comparing between desert ponds, DP3 is

506 significantly different from all other ponds for $\delta^{13} \mathrm{C} \quad(\mathrm{p}=0.0064)$ and DP4 has a

507 significantly larger $\delta^{15} \mathrm{~N}$ than the other ponds $(\mathrm{p}=0.0239)$. Muscle tissue isotopes

508 analysis therefore suggests that fish in the desert pond have different diets and therefore

509 different ecological niches relative to the populations from the Red Sea coast and some

510 desert ponds have distinct isotope signatures in comparison to other desert ponds. 


\section{Discussion}

513 Our sampling of Aphanius dispar along the Red Sea coastline of the Arabian Desert

514 provides insight to previously uncharacterized sites hosting populations in both near-

515 freshwater water ponds as well as in sheltered coastal marine habitats. In contrast to the

516 often ephemeral habitats occupied by the African turquoise killifish, Nothobranchius

517 furzeri (Furness, 2016), the survival and persistence of the Arabian pupfish seems to

518 depend on constant groundwater discharge and irregular rainfall events. Hydrological

519 mapping and genetic analyses reveal that due to sporadic flash floods occurring in the

520 region (Deng et al., 2015) fish may literally be washed from desert ponds out to the Red

521 Sea. The genetic population units comprised an admixture of pupfish from the two

522 different environments, desert pond and seawater individuals. We detected four main

523 genetic clusters, which mostly grouped desert fish with Red Sea individuals based on a

524 latitudinal gradient. Due to little hydrological connectivity among desert ponds, pupfish

525 from the desert (or 'oases') are alternately rapidly carried out to very different

526 environmental conditions in the Red Sea along wadis during flash flood events. The

527 change in environmental condition is though not accompanied by population structure,

528 contrary to many other study systems across different environmental gradients with

529 populations differentiating with distance or environment (Sexton et al., 2014).

530

\section{Ecological acclimation}

532 Surviving a 'washout' event from a desert pond with less than $1 \mathrm{ppt}$ in salinity to the

533 highly saline Red Sea (with an average salinity of $43 \mathrm{ppt}$ ) requires a considerable

534 acclimation capacity. Many killifish species are euryhaline and can tolerate large salinity 
535 changes in the environment. Fundulus heteroclitus has been shown to undergo a large

536 range of physiological changes, from drinking rates to changes in acid base regulation

537 (Wood \& Marshall, 1994). Nonetheless, Fundulus species, albeit tolerant to large salinity

538 ranges, have diverged into species adapted to specific environmental conditions

539 (Whitehead, 2010). Interestingly, we found the same genetic populations of A. dispar

540 living in both desert ponds and seawater. The hypothesized saltwater evolutionary origin

541 of the Aphanius genus ${ }^{19}$ provides a potential explanation for the tolerance of $A$. dispar

542 when moved from near-freshwater ponds to a highly saline environment. However, it is

543 not just temperature and salinity that differ between the desert ponds and the Red Sea

544 coastal environments. We also see an ecological divergence in tissue stable isotopes

545 between desert and seawater sites, even from within the same genetic population unit.

546 The seawater fish muscle tissues were depleted in ${ }^{15} \mathrm{~N}$ and more enriched in ${ }^{13} \mathrm{C}$ than their

547 freshwater counterparts. Similar signatures have previously been found when comparing

548 freshwater and saltwater fish, although the fish species in each of the environments

549 differed (Fuller et al., 2012; Robson et al., 2016). Similarly, for anadromous species such

550 as salmon that travel from fresh to saltwater, an increase in ${ }^{13} \mathrm{C}$ is exhibited when resident

551 in seawater habitats (Litz et al., 2017). Higher levels of ${ }^{15} \mathrm{~N}$, found here for the desert

552 ponds, is often correlated with higher trophic hierarchy levels (Zanden \& Rasmussen,

553 1999). For A. dispar, however, it is difficult to isolate the potential influences of habitat-

554 related variability in the basal isotopic values of the food web from the potential trophic

555 shifts (McMahon, Hamady, \& Thorrold, 2013; Post, 2002).

557 Genetic divergence 
558 Environmental differences leading to ecological divergence can drive adaptation and

559 eventually speciation (Arnegard et al., 2014). Despite large ecological difference in prey

560 and habitat niche, there is little genetic difference between the desert pond fish and the

561 geographically-corresponding seawater fish. This could give a hint that 'washout events'

562 occur frequently enough to create enough migration from the desert ponds to the seawater

563 sites, or that, as previously shown in other killifish species (Whitehead, Roach, Zhang, \&

564 Galvez, 2012), the Arabian killifish has a large capacity for rapid and long-lasting plastic

565 responses to environmental change. We found only five putative outlier single nucleotide

566 loci that could be under selection between all desert pond inhabitants and seawater fish,

567 and only three that can be functionally annotated. Perforin 1 (prfl), a gene to which one

568 of the outliers was successfully blasted (see Table 3), has key functions in the immune

569 response and forms part of killer T-cells, indicating a potential adaptive change to the

570 highly saline environment in the Red Sea. This particular function has been seen to be

571 conserved in many fish species (Nakanishi, Toda, Shibasaki, \& Somamoto, 2011; Toda,

572 Araki, Moritomo, \& Nakanishi, 2011). Interestingly, in wild salmon, perforin-mediated

573 apoptotic processes were important in survival when migrating back to freshwater

574 spawning grounds from seawater (Miller et al., 2011). Environmental changes are also

575 associated with a SNP in the ATPase Family gene 3 (afg3) previously attributed to stress

576 and biosynthesis and with an increased expression in trout after a starvation period

577 (Rescan et al., 2007). A hint towards its importance in seawater acclimation could be

578 related to an increase in mitochondrion-rich cells and ATPase activity due to a

579 physiological demand of acid-base and ion regulation in saltwater (Lee, Hwang, Shieh,

$580 \&$ Lin, 2000). 
582 One of the desert ponds, the Al Lith hot spring (site DP3), had high temperatures $583\left(>38^{\circ} \mathrm{C}\right)$ and a different chemical signature, such as a high amount of silica. Life in such 584 hot water could potentially provoke adaptive signals in the genome. However, only one 585 putative outlier was found for the inhabitants of the hot spring in comparison to other 586 desert ponds. therefore hinting to phenotypic plasticity, as for the case of the Magadi 587 tilapia (Alcolapia grahami). Alcolapia grahami lives in hot springs in Kenya and was 588 recently described to have the highest upper critical temperature recorded for a fish (45.6 $589{ }^{\circ} \mathrm{C}$ (Wood et al., 2016)). Despite the extreme environmental conditions, genetic studies 590 did not find population differences when compared to tilapia of less extreme 591 environmental conditions at close proximity (Wilson et al., 2004; Zaccara et al., 2014). 592 Low numbers of putative outlier SNPs were also detected, suggesting some ongoing gene 593 flow and admixture (Ford et al., 2015), which could be the case for our A. dispar samples 594 from the Al Lith hot spring. Despite the lack of loci under selection, connectivity between 595 desert ponds is low and there is limited gene flow, as indicated by large genetic distances 596 between the hot spring and other desert ponds, suggesting isolation and divergence 597 between these habitats. For the pupfish in the hot spring, we could detect a differentiated 598 ecological signature in tissue stable isotopes compared to the other desert ponds. 599 Although contradicting the findings on the Magadi tilapia, where the hot spring site 600 revealed carbon isotope tissue enrichment (Kavembe, Kautt, Machado-Schiaffino, \& 601 Meyer, 2016), A. dispar from the $\mathrm{Al}$ Lith hot spring have lower values of ${ }^{13} \mathrm{C}$ in their 602 muscle tissue. One possible explanation for this result might be the turbidity of the hot 
603 spring site, due to a large amount of suspended silica, as carbon stable isotope depletion

604 was previously associated with turbidity in the environment (Nahon et al., 2013).

605

606 Anthropogenic impacts on desert fish populations

607 Besides natural environmental conditions that are reflected in the isotopic signature of the

608 pupfish, anthropogenic impacts can also be detected. In the case of DP4, we found an

609 isotopic as well as genetic signature of human disturbance. Fish tissues here are more ${ }^{15} \mathrm{~N}$

610 enriched in comparison to other locations, which indicates an accumulation of the heavier

611 isotope element possibly due to isolation of this pond (Amundson et al., 2003; Szpak,

612 2014). In this site, there is evidence of agricultural activity, most likely utilizing

613 groundwater in the area, which in turn might lower the water table and disconnect this

614 location from others. Furthermore, there is a dam structure $15 \mathrm{~km}$ upstream of DP4 most

615 likely restricting the water availability downstream. Even if topographic mapping shows

616 a hydrological connection between DP4 and SW4, it seems that human interference here

617 inhibits any flow of water to the sea. This hypothesis would explain the genetic

618 differentiation for this particular site, which seems to be undergoing a population

619 bottleneck. The fish in this site have in fact an increased number of private alleles and

620 low genetic diversity, indicated by low heterozygosity. Even though the inbreeding

621 coefficient was is low, this result is most likely due to low genetic differentiation within

622 the population used in the calculation. Pairwise kinship reveals most individuals within

623 this site to be highly related, and the effective population size is very low. It therefore

624 seems that use of water in this area has isolated this population, restricting its gene flow

625 and its resilience. 
627 In the northern part of the Saudi Arabian coast, A. dispar in desert ponds and saltwater

628 locations do not cluster together genetically, as it is seen in the southern parts, albeit

629 hydrological connectivity potential. Here the desert pond fish are genetically closer to

630 each other, as are the seawater fish, with a clear division between desert and Red Sea

631 sample sites. There are two plausible reasons for this disconnection. The northern regions

632 receive less rainfall (El Kenawy \& McCabe, 2016) and hence any hydrological

633 connectivity between the desert and the sea will be much lower. The observed strong

634 genetic divergence though is most likely caused by the 'upstream' construction of the

635 Rabigh Dam (completed 2008), which was built for municipal water supply and flood

636 control. Hence, even with rain events the water, and therefore the pupfish, can no longer

637 reach the sea. For this reason, A. dispar populations are now diverging without the

638 presence of gene flow through new migrants. A similar anthropogenic impact was found

639 for desert fish of the Colorado River area, where natural flooding occurred regularly until

640 the construction of dams that drastically changed the water availability and had a major

641 impact on the distribution of desert fish (Hillyard, Podrabsky, \& van Breukelen, 2015).

642

643 Fish living in desert regions have long been a conservation concern, with a large number

644 of such species being under threat or endangered, often due to the expansion of desert

645 agriculture and increasing global temperatures (Van Haverbeke et al., 2013). Although

646 the Dead Sea subspecies (A. dispar richardsoni) is considered endangered (Goren, 2014),

647 A. dispar itself is not considered to be endangered because it has stable populations

648 widely distributed throughout the Arabian region (Freyhof, 2014). The species' capacity 
bioRxiv preprint doi: https://doi.org/10.1101/2021.05.14.444120; this version posted May 16, 2021. The copyright holder for this preprint (which

was not certified by peer review) is the author/funder, who has granted bioRxiv a license to display the preprint in perpetuity. It is made available under aCC-BY-NC-ND 4.0 International license.

649 to acclimate and survive challenging environmental fluctuations likely plays a major role

650 in its success in this region. However, our results show that despite the large capacity of

651 A. dispar to acclimate and adapt to different environments and defy the constraints of

652 living in restricted desert environments, anthropogenic water use can dramatically alter

653 the population dynamics of the Arabian pupfish.

654 
Al-Kahem-Al-Balawi, H. F., Al-Ghanim, K. A., Ahmad, Z., Temraz, T. A., Al-Akel, A. S., Al-Misned, F., \& Annazri, H. (2008). A threatened fish species (Aphanius dispar) in Saudi Arabia, a case study. Pakistan Journal of Biological Sciences $\square$ :

660

661 PJBS, 11 (19), 2300-2307. Retrieved from

662 http://www.ncbi.nlm.nih.gov/pubmed/19137861

663

664

665

666

667

668

669

670

671

672

673

674

675

676

677

678

679

680

681

682

683

684

685

686

687

688

689

690

691

692

693

694

695

696

697

698

699

Amundson, R., Austin, A. T., Schuur, E. A. G., Yoo, K., Matzek, V., Kendall, C., ... Baisden, W. T. (2003). Global patterns of the isotopic composition of soil and plant nitrogen. Global Biogeochemical Cycles, 17 (1). https://doi.org/10.1029/2002GB001903

Arnegard, M. E., McGee, M. D., Matthews, B., Marchinko, K. B., Conte, G. L., Kabir, S., ... Schluter, D. (2014). Genetics of ecological divergence during speciation. Nature, 511 (7509), 307-311. https://doi.org/10.1038/nature13301

Bennett, W. A., \& Beitinger, T. L. (1997). Temperature Tolerance of the Sheepshead Minnow, Cyprinodon variegatus. Copeia, 1, 77. https://doi.org/10.2307/1447842

Bolger, A. M., Lohse, M., \& Usadel, B. (2014). Trimmomatic: a flexible trimmer for Illumina sequence data. Bioinformatics (Oxford, England), 30, 2114-2120. https://doi.org/10.1093/bioinformatics/btu170

Bouzat, J. L. (2010). Conservation genetics of population bottlenecks: the role of chance, selection, and history. Conservation Genetics, 11 (2), 463-478. https://doi.org/10.1007/s10592-010-0049-0

Bowman, A., \& Azzalini, A. W. (2014). R package “sm”: nonparametric smoothing methods (version 2.2-5.4). Retrieved from http://www.stats.gla.ac.uk/ adrian/sm, http://azzalini.stat.unipd.it/Book_sm

Catchen, J., Hohenlohe, P. A., Bassham, S., Amores, A., \& Cresko, W. A. (2013). Stacks: an analysis tool set for population genomics. Molecular Ecology, 22 (11), 3124-3140. https://doi.org/10.1111/mec.12354

Danecek, P., Auton, A., Abecasis, G., Albers, C. A., Banks, E., DePristo, M. A., ... Durbin, R. (2011). The variant call format and VCFtools. Bioinformatics, 27 (15), 2156-2158. https://doi.org/10.1093/bioinformatics/btr330

Deng, L., McCabe, M. F., Stenchikov, G., Evans, J. P., Kucera, P. A., Deng, L., ... Kucera, P. A. (2015). Simulation of Flash-Flood-Producing Storm Events in Saudi Arabia Using the Weather Research and Forecasting Model. Journal of Hydrometeorology, 16 (2), 615-630. https://doi.org/10.1175/JHM-D-14-0126.1

Do, C., Waples, R. S., Peel, D., Macbeth, G. M., Tillett, B. J., \& Ovenden, J. R. (2014). NeEstimator v2: re-implementation of software for the estimation of contemporary effective population size ( $N_{e}$ ) from genetic data. Molecular Ecology Resources, 14 (1), 209-214. https://doi.org/10.1111/1755-0998.12157

Doebeli, M., \& Dieckmann, U. (2003). Speciation along environmental gradients. Nature, 421 (6920), 259-264. https://doi.org/10.1038/nature01274

Earl, D. A., \& vonHoldt, B. M. (2012). STRUCTURE HARVESTER: a website and program for visualizing STRUCTURE output and implementing the Evanno method. Conservation Genetics Resources, 4 (2), 359-361. https://doi.org/10.1007/s12686-011-9548-7

Ehrich, D., Tarroux, A., Stien, J., Lecomte, N., Killengreen, S., Berteaux, D., \& Yoccoz, 
731

732

733

734

735

736

737

738

739

740

741

742

743

744

745

N. G. (2011). Stable isotope analysis: modelling lipid normalization for muscle and eggs from arctic mammals and birds. Methods in Ecology and Evolution, 2 (1), 6676. https://doi.org/10.1111/j.2041-210X.2010.00047.x

El Kenawy, A. M., \& McCabe, M. F. (2016). A multi-decadal assessment of the performance of gauge- and model-based rainfall products over Saudi Arabia: climatology, anomalies and trends. International Journal of Climatology, 36 (2), 656-674. https://doi.org/10.1002/joc.4374

Evanno, G., Regnaut, S., \& Goudet, J. (2005). Detecting the number of clusters of individuals using the software STRUCTURE: a simulation study. Molecular Ecology, 14 (8), 2611-2620. https://doi.org/10.1111/j.1365-294X.2005.02553.x

Fisher, S. G., Gray, L. J., Grimm, N. B., \& Busch, D. E. (1982). Temporal Succession in a Desert Stream Ecosystem Following Flash Flooding. Ecological Monographs, 52 (1), 93-110. https://doi.org/10.2307/2937346

Foll, M., \& Gaggiotti, O. (2008). A Genome-Scan Method to Identify Selected Loci Appropriate for Both Dominant and Codominant Markers: A Bayesian Perspective. Genetics, 180 (2). Retrieved from http://www.genetics.org/content/180/2/977

Ford, A. G. P., Dasmahapatra, K. K., Rüber, L., Gharbi, K., Cezard, T., \& Day, J. J. (2015). High levels of interspecific gene flow in an endemic cichlid fish adaptive radiation from an extreme lake environment. Molecular Ecology, 24 (13), 34213440. https://doi.org/10.1111/MEC.13247

Freyhof, J. (2014). Aphanius dispar.

Fuller, B. T., Müldner, G., Van Neer, W., Ervynck, A., Richards, M. P., Cooremans, B., ... Richards, M. P. (2012). Carbon and nitrogen stable isotope ratio analysis of freshwater, brackish and marine fish from Belgian archaeological sites (1st and 2nd millennium AD). Journal of Analytical Atomic Spectrometry, 27 (5), 807. https://doi.org/10.1039/c2ja10366d

Furness, A. I. (2016). The evolution of an annual life cycle in killifish: adaptation to ephemeral aquatic environments through embryonic diapause. Biological Reviews, 91 (3), 796-812. https://doi.org/10.1111/brv.12194

Gaggiotti, O. E. (2003). Genetic threats to population persistence. Ann. Zool. Fennici, 40 (40), 155-168. Retrieved from http://www.annzool.net/PDF/anz40-free/anz40155.pdf

Gat, J. R. (1996). Oxygen and hydropgen iostopes in the hydrologic cycle. Annual Review of Earth and Planetary Sciences, 24 (1), 225-262. https://doi.org/10.1146/annurev.earth.24.1.225

Gibson, J. J., Birks, S. J., \& Edwards, T. W. D. (2008). Global prediction of $\delta_{\text {A }}$ and $\delta^{2}$ $\mathrm{H}-\delta^{18} \mathrm{O}$ evaporation slopes for lakes and soil water accounting for seasonality. Global Biogeochemical Cycles, 22 (2), n/a-n/a. https://doi.org/10.1029/2007GB002997

Gibson, J. J., \& Reid, R. (2014). Water balance along a chain of tundra lakes: A 20-year isotopic perspective. Journal of Hydrology, 519, 2148-2164. https://doi.org/10.1016/j.jhydrol.2014.10.011

Goren, M. (2014). Aphanius dispar ssp. richardsoni.

Haas, R. (1982). Notes on the ecology of Aphanius dispar (Pisces, Cyprinodontidae) in the Sultanate of Oman. Freshwater Biology, 12 (1), 89-95. https://doi.org/10.1111/j.1365-2427.1982.tb00605.x 
746

747

748

749

750

751

752

753

754

755

756

757

758

759

760

761

762

763

764

765

766

767

768

769

770

771

772

773

774

775

776

777

778

779

780

781

782

783

784

785

786

787

788

789

790

791

Hillyard, S. D., Podrabsky, J. E., \& van Breukelen, F. (2015). Desert Environments. In Extremophile Fishes (pp. 59-83). Cham: Springer International Publishing. https://doi.org/10.1007/978-3-319-13362-1_4

Hopken, M. W., Douglas, M. R., \& Douglas, M. E. (2013). Stream hierarchy defines riverscape genetics of a North American desert fish. Molecular Ecology, 22 (4), 956-971. https://doi.org/10.1111/mec.12156

Hrbek, T., \& Meyer, A. (2003). Closing of the Tethys Sea and the phylogeny of Eurasian killifishes (Cyprinodontiformes: Cyprinodontidae). Journal of Evolutionary Biology, 16 (1), 17-36. https://doi.org/10.1046/j.1420-9101.2003.00475.x

Jakobsson, M., \& Rosenberg, N. A. (2007). CLUMPP: a cluster matching and permutation program for dealing with label switching and multimodality in analysis of population structure. Bioinformatics, 23 (14), 1801-1806.

https://doi.org/10.1093/bioinformatics/btm233

Jombart, T. (2008). adegenet: a R package for the multivariate analysis of genetic markers. Bioinformatics, 24 (11), 1403-1405. https://doi.org/10.1093/bioinformatics/btn129

Kavembe, G. D., Franchini, P., Irisarri, I., Machado-Schiaffino, G., \& Meyer, A. (2015). Genomics of Adaptation to Multiple Concurrent Stresses: Insights from Comparative Transcriptomics of a Cichlid Fish from One of Earth's Most Extreme Environments, the Hypersaline Soda Lake Magadi in Kenya, East Africa. Journal of Molecular Evolution, 81 (3-4), 90-109. https://doi.org/10.1007/s00239-015-9696-6

Kavembe, G. D., Kautt, A. F., Machado-Schiaffino, G., \& Meyer, A. (2016). Ecomorphological differentiation in Lake Magadi tilapia, an extremophile cichlid fish living in hot, alkaline and hypersaline lakes in East Africa. Molecular Ecology, 25 (7), 1610-1625. https://doi.org/10.1111/mec.13461

Kelley, J. L., Peyton, J. T., Fiston-Lavier, A.-S., Teets, N. M., Yee, M.-C., Johnston, J. S., ... Denlinger, D. L. (2014). Compact genome of the Antarctic midge is likely an adaptation to an extreme environment. Nature Communications, 5, ncomms5611. https://doi.org/10.1038/ncomms5611

Lee, T. H., Hwang, P. P., Shieh, Y. E., \& Lin, C. H. (2000). The relationship between 'deep-hole' mitochondria-rich cells and salinity adaptation in the euryhaline teleost, Oreochromis mossambicus. Fish Physiology and Biochemistry, 23 (2), 133-140. https://doi.org/10.1023/A:1007818631917

Lischer, H. E. L., \& Excoffier, L. (2012). PGDSpider: an automated data conversion tool for connecting population genetics and genomics programs. Bioinformatics, 28 (2), 298-299. https://doi.org/10.1093/bioinformatics/btr642

Litz, M. N. C., Miller, J. A., Copeman, L. A., Teel, D. J., Weitkamp, L. A., Daly, E. A., \& Claiborne, A. M. (2017). Ontogenetic shifts in the diets of juvenile Chinook Salmon: new insight from stable isotopes and fatty acids. Environmental Biology of Fishes, 100 (4), 337-360. https://doi.org/10.1007/s10641-016-0542-5

Martin, C. H., Crawford, J. E., Turner, B. J., \& Simons, L. H. (2016). Diabolical survival in Death Valley: recent pupfish colonization, gene flow and genetic assimilation in the smallest species range on earth. Proceedings of the Royal Society B: Biological Sciences, 283 (1823), 20152334. https://doi.org/10.1098/rspb.2015.2334

McMahon, K. W., Hamady, L. L., \& Thorrold, S. R. (2013). A review of ecogeochemistry approaches to estimating movements of marine animals. 
792

793

794

795

796

797

798

799

800

801

802

803

804

805

806

807

808

809

810

811

812

813

814

815

816

817

818

819

820

821

822

823

824

825

826

827

828

829

830

831

832

833

834

835

836

837

Limnology and Oceanography, 58 (2), 697-714.

https://doi.org/10.4319/lo.2013.58.2.0697

Meffe, G. K., \& Vrijenhoek, R. C. (1988). Conservation Genetics in the Management of Desert Fishes. Conservation Biology, 2 (2), 157-169. https://doi.org/10.1111/j.15231739.1988.tb00167.x

Meirmans, P. G., \& Van Tienderen, P. H. (2004). Genotype and Genodive: two programs for the analysis of genetic diversity of asexual organisms. Molecular Ecology Notes, 4 (4), 792-794. https://doi.org/10.1111/j.1471-8286.2004.00770.x

Miller, K. M., Li, S., Kaukinen, K. H., Ginther, N., Hammill, E., Curtis, J. M. R., ... Farrell, A. P. (2011). Genomic Signatures Predict Migration and Spawning Failure in Wild Canadian Salmon. Science, 331 (6014), 214-217. https://doi.org/10.1126/science.1196901

Moore, T. Y., Cooper, K. L., Biewener, A. A., \& Vasudevan, R. (2017). Unpredictability of escape trajectory explains predator evasion ability and microhabitat preference of desert rodents. Nature Communications, 8 (1), 440. https://doi.org/10.1038/s41467017-00373-2

Nahon, S., Richoux, N. B., Kolasinski, J., Desmalades, M., Ferrier Pages, C., Lecellier, G., ... Berteaux Lecellier, V. (2013). Spatial and Temporal Variations in Stable Carbon $(\delta 13 \mathrm{C})$ and Nitrogen $(\delta 15 \mathrm{~N})$ Isotopic Composition of Symbiotic Scleractinian Corals. PLoS ONE, 8 (12), e81247. https://doi.org/10.1371/journal.pone.0081247

Nakanishi, T., Toda, H., Shibasaki, Y., \& Somamoto, T. (2011). Cytotoxic T cells in teleost fish. Developmental \& Comparative Immunology, 35 (12), 1317-1323. https://doi.org/10.1016/j.dci.2011.03.033

NASA Jet Propulsion Laboratory. (2009). ASTER Global Digital Elevation Model. https://doi.org/10.5067/ASTER/ASTGTM.002

Paul, D., Skrzypek, G., \& Fórizs, I. (2007). Normalization of measured stable isotopic compositions to isotope reference scales - a review. Rapid Communications in Mass Spectrometry, 21 (18), 3006-3014. https://doi.org/10.1002/rcm.3185

Peterson, B. K., Weber, J. N., Kay, E. H., Fisher, H. S., \& Hoekstra, H. E. (2012). Double Digest RADseq: An Inexpensive Method for De Novo SNP Discovery and Genotyping in Model and Non-Model Species. PLoS ONE, 7 (5), e37135. https://doi.org/10.1371/journal.pone.0037135

Post, D. M. (2002). Using Stable Isotopes to Estimate Trophic Position: Models,Methods and Assumptions. Ecology, 83 (3), 703-718. https://doi.org/10.1890/0012-9658 (2002)083[0703:USITET]2.0.CO;2

Pritchard, J. K., Stephens, M., \& Donnelly, P. (2000). Inference of population structure using multilocus genotype data. Genetics, 155 (2), 945-959. Retrieved from http://www.pubmedcentral.nih.gov/articlerender.fcgi?artid=1461096\&tool=pmcentr ez\&rendertype $=$ abstract

Rescan, P.-Y., Montfort, J., Rallière, C., Le Cam, A., Esquerré, D., \& Hugot, K. (2007). Dynamic gene expression in fish muscle during recovery growth induced by a fasting-refeeding schedule. BMC Genomics, 8 (1), 438. https://doi.org/10.1186/1471-2164-8-438

Robson, H. K., Andersen, S. H., Clarke, L., Craig, O. E., Gron, K. J., Jones, A. K. G., ... Heron, C. (2016). Carbon and nitrogen stable isotope values in freshwater, brackish 
838

839

840

841

842

843

844

845

846

847

848

849

850

851

852

853

854

855

856

857

858

859

860

861

862

863

864

865

866

867

868

869

870

871

872

873

874

875

876

877

878

879

880

881

882

883 and marine fish bone collagen from Mesolithic and Neolithic sites in central and northern Europe. Environmental Archaeology, 21 (2), 105-118.

https://doi.org/10.1179/1749631415Y.0000000014

Rosenberg, N. A. (2003). distruct: a program for the graphical display of population structure. Molecular Ecology Notes, 4 (1), 137-138. https://doi.org/10.1046/j.14718286.2003.00566.x

Rousset, F. (2008). genepop'007: a complete re-implementation of the genepop software for Windows and Linux. Molecular Ecology Resources, 8 (1), 103-106. https://doi.org/10.1111/j.1471-8286.2007.01931.x

Seeb, L. W., Waples, R. K., Limborg, M. T., Warheit, K. I., Pascal, C. E., \& Seeb, J. E. (2014). Parallel signatures of selection in temporally isolated lineages of pink salmon. Molecular Ecology, 23 (10), 2473-2485. https://doi.org/10.1111/mec.12769

Sexton, J. P., Hangartner, S. B., \& Hoffmann, A. A. (2014). Genetic isolation by environment or distance: which pattern of gene flow is most common? Evolution, 68 (1), 1-15. https://doi.org/10.1111/evo.12258

Sharp, Z. (2007). Principles of stable isotope geochemistry. Pearson/Prentice Hall.

Szpak, P. (2014). Complexities of nitrogen isotope biogeochemistry in plant-soil systems: implications for the study of ancient agricultural and animal management practices. Frontiers in Plant Science, 5, 288. https://doi.org/10.3389/fpls.2014.00288

Toda, H., Araki, K., Moritomo, T., \& Nakanishi, T. (2011). Perforin-dependent cytotoxic mechanism in killing by CD8 positive T cells in ginbuna crucian carp, Carassius auratus langsdorfii. Developmental \& Comparative Immunology, 35 (1), 88-93. https://doi.org/10.1016/j.dci.2010.08.010

Van Haverbeke, D. R., Stone, D. M., Coggins, L. G., \& Pillow, M. J. (2013). Long-Term Monitoring of an Endangered Desert Fish and Factors Influencing Population Dynamics. Journal of Fish and Wildlife Management, 4 (1), 163-177. https://doi.org/10.3996/082012-JFWM-071

Wang, I. J., \& Bradburd, G. S. (2014). Isolation by environment. Molecular Ecology, 23 (23), 5649-5662. https://doi.org/10.1111/mec.12938

Whitehead, A. (2010). The evolutionary radiation of diverse osmotolerant physiologies in killifish (Fundulus sp.). Evolution. https://doi.org/10.1111/j.15585646.2010.00957.x

Whitehead, A., Galvez, F., Zhang, S., Williams, L. M., \& Oleksiak, M. F. (2011). Functional genomics of physiological plasticity and local adaptation in killifish. The Journal of Heredity, 102 (5), 499-511. https://doi.org/10.1093/jhered/esq077

Whitehead, A., Roach, J. L., Zhang, S., \& Galvez, F. (2012). Salinity- and populationdependent genome regulatory response during osmotic acclimation in the killifish ( Fundulus heteroclitus ) gill, 1293-1305. https://doi.org/10.1242/jeb.062075

Wilson, P., Wood, C., Walsh, P., Bergman, A., Bergman, H., Laurent, P., \& White, B. (2004). Discordance between Genetic Structure and Morphological, Ecological, and Physiological Adaptation in Lake Magadi Tilapia. Physiological and Biochemical Zoology, 77 (4), 537-555. https://doi.org/10.1086/422054

Wood, C. M., Brix, K. V, De Boeck, G., Bergman, H. L., Bianchini, A., Bianchini, L. F., ... Ojoo, R. O. (2016). Mammalian metabolic rates in the hottest fish on earth. Scientific Reports, srep26990. https://doi.org/10.1038/srep26990 
884 Wood, C. M., \& Marshall, W. S. (1994). Ion Balance, Acid-Base Regulation, and

885 Chloride Cell Function in the Common Killifish, Fundulus heteroclitus: A

886 Euryhaline Estuarine Teleost. Estuaries, 17 (1), 34. https://doi.org/10.2307/1352333

887

888

Zaccara, S., Crosa, G., Vanetti, I., Binelli, G., Harper, D. M., Mavuti, K. M., ... Britton,

889

890 J. R. (2014). Genetic and morphological analyses indicate high population mixing

891

892

893

894

895

896

897

898 in the endangered cichlid Alcolapia flock of East Africa. Conservation Genetics, 15 (2), 429-440. https://doi.org/10.1007/s10592-013-0551-2

Zanden, M. J. Vander, \& Rasmussen, J. B. (1999). Primary consumer $\square$ ? 13 C and? 15 N and the trophic position of aquatic consumers. Ecology, 80 (4), 1395-1404. https://doi.org/10.1890/0012-9658 (1999)080[1395:PCCANA]2.0.CO;2

Zanden, M. J. Vander, \& Rasmussen, J. B. (2001). Variation in $\delta^{15} \mathrm{~N}$ and $\delta^{13} \mathrm{C}$ trophic fractionation: Implications for aquatic food web studies. Limnology and Oceanography, 46 (8), 2061-2066. https://doi.org/10.4319/lo.2001.46.8.2061 


\section{Acknowledgments}

900 This study was supported by the King Abdullah University of Science and Technology

901 (KAUST). We are very grateful to the KAUST Coastal and Marine Resources Core Lab

902 and KAUST Government Affairs for their support in finding desert ponds, obtaining 903 permits and aiding in the field. We thank the KAUST Integrative Systems Biology

904 Laboratory and the KAUST Biosciences Core Laboratory for support and assistance.

905

906 Author contributions: C.S. designed and managed the field collection. C.S, L.C.B \&

907 J.N. performed the sample collection. L.C.B. and J.N. with the supervision of C.S. 908 prepared the samples for DNA sequencing and tissue isotope measurements. M.L.B.

909 provided reagents. J.N. performed chemical water analyses and L.C.B. analyzed the

910 tissue isotope data. S.D.P., Y.A.L. and M.F.M. created hydrological mapping and

911 analyzed water isotopes. C.S. analyzed the sequencing data, performed population

912 genetic analyses with help from J.S. and integrated all datasets. C.S. \& T.R. wrote the

913 paper; all authors provided input to and approved the final version of the manuscript.

914

\section{Additional information:}

916 Raw sequencing data have been deposited on NCBI under BioProject ID PRJNA311159.

917 Final SNP vcf file is available as Supplementary Material. Correspondence and requests

918 for materials should be addressed to T.R. or C.S.

919

920 Competing interests

921 The authors declare no competing interests. 


\section{$922 \quad$ Figure legends}

923 Figure 1: Locations of all sampling sites over a 1,100 km stretch of the Saudi Arabian

924 coastline. Grey circles represent desert ponds without the presence of Aphanius dispar.

925 Sites with pupfish are colored $(n=11)$ and classified as desert ponds (DP) or seawater

926 lagoons (SW). The top two pictures show a male and female A. dispar, respectively. The

927 center picture is an example of a desert pond (DP2), below which is the Al Lith hotspring

928 (DP3). The bottom picture shows an example of a seawater site (SW4). The map was

929 created using ArcGIS 10.5 (www.arcgis.com).

930

931 Figure 2: Hydrological modeling. Latitudinal 2D overview of Saudi Arabian coastline

932 with Aphanius dispar collection sites indicated with fish icons (left) and 3D close-ups on

933 three regions with predicted hydrological flow. Maps were produced with Google Earth

934 imagery (Google Earth 7.1.2.2041; December 31, 2016) and ArcGIS 10.5 software

935 (www.arcgis.com).

936

937 Figure 3: Heatmap of $\mathrm{F}_{\mathrm{ST}}$ values of pairwise population comparisons based on 5,955

938 SNPs. Location abbreviations as in Table 1 ( $\mathrm{DP}=$ desert pond, $\mathrm{SW}=$ seawater).

940 Figure 4: Aphanius dispar population structure with a) $\mathrm{K}=4$ and b) $\mathrm{K}=8$. Each individual

941 in the different sites (y-Axis) are plotted with colours representing the probability of each

942 individual to be assigned to a certain cluster. 
944 Figure 5: Scatterplot of principal component analysis evaluating the genetic structure

945 between all analyzed Aphanius dispar individuals based on 5,955 loci. Eigenvalues

946 represent the amount of genetic diversity shown by each principal component. a) PCA of

947 principal components 1 and 2. b) PCA of principal components 1 and 3.

948

949 Figure 6: Ratio of stable isotopes of carbon and nitrogen in muscle tissue of Aphanius

950 dispar, including fish from brackish water ponds and saltwater in the Red Sea. Error bars

951 represent the standard error per location

952 
953 Table 1: Sampling locations, characteristics and selected water parameters (for full water

954 measurements refer to Supplementary Table 1) measured by CTD or Aquakem. A dash

955 indicates that no reliable measurement was obtained.

\begin{tabular}{|c|c|c|c|c|c|c|c|c|c|}
\hline Site & Type & $\begin{array}{c}\text { Temperature } \\
\left({ }^{\circ} \mathbf{C}\right)\end{array}$ & $\begin{array}{c}\text { Conductivity } \\
(\mu \mathrm{S} / \mathrm{cm})\end{array}$ & $\begin{array}{l}\text { Salinity } \\
\text { (ppt) }\end{array}$ & $\begin{array}{c}\mathbf{O 2} \\
(\mathbf{p p m})\end{array}$ & pH & $\begin{array}{c}\text { Chlorides } \\
\text { (ppm) }\end{array}$ & $\begin{array}{l}\text { Silica } \\
\text { (ppb) }\end{array}$ & $\begin{array}{l}\text { pupfish } \\
\text { present }\end{array}$ \\
\hline SW5 & Sea & 21.77 & $58,340.47$ & 41.93 & 2.87 & 8.71 & 27.10 & 306.02 & yes \\
\hline SW4 & Sea & 27.90 & $66,952.99$ & 42.75 & 3.39 & 9.01 & 29.59 & 314.61 & yes \\
\hline SW3 & Sea & 22.82 & $58,685.99$ & 41.19 & 4.40 & 9.10 & 2.15 & 104.57 & yes \\
\hline SW2 & Sea & 24.80 & $64,966.91$ & 44.20 & 3.43 & 8.37 & $36,677.27$ & 517.96 & yes \\
\hline SW1 & Sea & 20.90 & $59,185.03$ & 43.49 & 3.93 & 8.37 & 36.06 & 31.97 & yes \\
\hline DP6 & Pond & 31.42 & $1,663.76$ & 0.74 & 7.75 & 9.41 & 282.41 & $34,511.49$ & yes \\
\hline DP5 & Pond & 30.93 & $1,760.39$ & 0.79 & 8.32 & 9.39 & 294.11 & $59,944.24$ & yes \\
\hline DP4 & Pond & 26.44 & $2,004.49$ & 0.99 & 6.14 & 8.31 & 278.57 & $63,358.87$ & yes \\
\hline DP3 & $\begin{array}{c}\text { Hot } \\
\text { Spring }\end{array}$ & 38.42 & $1,916.49$ & 0.75 & 5.16 & 8.20 & 361.21 & $80,469.67$ & yes \\
\hline DP2 & Pond & 31.58 & $3,190.00$ & 1.45 & 4.35 & 8.31 & 734.37 & $38,017.18$ & yes \\
\hline DP1 & Pond & 29.93 & $1,720.00$ & 0.78 & 4.35 & 8.50 & 469.77 & $33,586.98$ & yes \\
\hline 28 & Sea & 27.65 & $64,108.41$ & 40.93 & 3.32 & 8.46 & - & - & no \\
\hline 27 & Sea & 21.77 & $65,110.01$ & 47.50 & 3.81 & 8.21 & - & - & no \\
\hline 26 & Sea & 18.18 & $51,228.77$ & 39.44 & 4.56 & 8.40 & - & - & no \\
\hline 25 & Sea & 22.60 & $57,621.28$ & 40.54 & 3.61 & 8.48 & - & - & no \\
\hline 24 & Sea & 12.08 & $46,285.24$ & 41.12 & 4.11 & 8.29 & - & - & no \\
\hline 23 & Sea & 21.74 & $63,528.52$ & 46.35 & 3.86 & 8.24 & - & - & no \\
\hline 15 & Pond & 21.28 & $5,825.19$ & 0.31 & 6.00 & 8.60 & 76.24 & $20,016.72$ & no \\
\hline 14 & Pond & 21.15 & $8,023.78$ & 0.43 & 3.10 & 7.71 & 115.34 & $38,414.86$ & no \\
\hline 13 & Pond & - & - & - & - & - & 103.07 & $5,016.26$ & no \\
\hline 11 & Pond & 28.91 & 898.74 & 0.41 & 6.33 & 8.04 & 86.54 & $38,664.80$ & no \\
\hline 9 & Pond & 33.54 & $1,025.76$ & 0.43 & 6.26 & 9.15 & 127.94 & $52,096.62$ & no \\
\hline 7 & Pond & 30.21 & $1,257.23$ & 0.56 & 4.49 & 8.05 & 196.26 & $76,975.60$ & no \\
\hline 6 & Pond & 28.31 & $1,164.95$ & 0.54 & 4.69 & 8.34 & 128.02 & $46,885.01$ & no \\
\hline 5 & Pond & 30.25 & 879.72 & 0.39 & 4.26 & 8.11 & 135.60 & $25,711.03$ & no \\
\hline 4 & Pond & - & - & - & - & - & 29.70 & $10,464.11$ & no \\
\hline 3 & Pond & 21.60 & $1,019.11$ & 0.54 & 5.32 & 8.25 & 166.66 & $45,331.00$ & no \\
\hline
\end{tabular}


958 Table 2: Genetic metrics for all 11 pupfish locations for 5,955 SNP loci per sampling site.

$959 \mathrm{~N}=$ number of individuals, Private $\mathrm{a}=$ number of private alleles, $\mathrm{Na}=$ average number of

960 alleles, $\mathrm{Ho}=$ observed heterozygosity, $\mathrm{He}=$ expected heterozygosity, $\mathrm{F}_{\mathrm{IS}}=$ inbreeding

961 coefficient, $\mathrm{Ne}=$ effective population size, $95 \% \mathrm{CI}=95 \%$ confidence intervals for $\mathrm{Ne}$,

962 mean $\mathrm{r}=$ average of pairwise kinship coefficient.

\begin{tabular}{|c|c|c|c|c|c|c|c|c|c|}
\hline Location & $\mathbf{N}$ & Private a & Na & Ho & He & $\mathbf{F}_{\text {IS }}$ & Ne & 95\% Cl & Mean r \\
\hline \hline DP1 & 29 & 15 & 1.74 & 0.21 & 0.23 & 0.07 & 1222 & $983-1614$ & 0.22 \\
\hline DP2 & 29 & 8 & 1.78 & 0.24 & 0.25 & 0.05 & 1851 & $1256-3511$ & 0.12 \\
\hline DP3 & 28 & 6 & 1.57 & 0.17 & 0.19 & 0.07 & 464 & $421-515$ & 0.12 \\
\hline DP4 & 27 & 27 & 1.31 & 0.08 & 0.08 & -0.02 & 51 & $49-52$ & 0.20 \\
\hline DP5 & 28 & 4 & 1.53 & 0.16 & 0.17 & 0.06 & 1497 & $1084-2416$ & 0.25 \\
\hline DP6 & 29 & 9 & 1.50 & 0.15 & 0.16 & 0.09 & 1713 & $1236-2782$ & 0.13 \\
\hline SW1 & 28 & 7 & 1.80 & 0.24 & 0.27 & 0.08 & 1149 & $882-1646$ & 0.27 \\
\hline SW2 & 29 & 13 & 1.80 & 0.23 & 0.26 & 0.09 & 5910 & $2229-i n f$ & 0.06 \\
\hline SW3 & 29 & 0 & 1.66 & 0.19 & 0.20 & 0.06 & 1702 & $1199-2925$ & 0.15 \\
\hline SW4 & 30 & 0 & 1.77 & 0.20 & 0.22 & 0.10 & 1645 & $1284-2286$ & 0.19 \\
\hline SW5 & 28 & 0 & 1.70 & 0.18 & 0.20 & 0.12 & 3917 & $2175-19493$ & 0.42 \\
\hline
\end{tabular}

963

964 
bioRxiv preprint doi: https://doi.org/10.1101/2021.05.14.444120; this version posted May 16, 2021. The copyright holder for this preprint (which was not certified by peer review) is the author/funder, who has granted bioRxiv a license to display the preprint in perpetuity. It is made available under ACC-BY-NC-ND 4.0 International license.

965 Table 3: Putative outlier loci between desert pond and red sea locations. Several pairwise

966 comparisons were performed, and the compared locations are indicated under "Locations

967 included". Sequences were blasted again NCBI and only successful blast hits are listed.

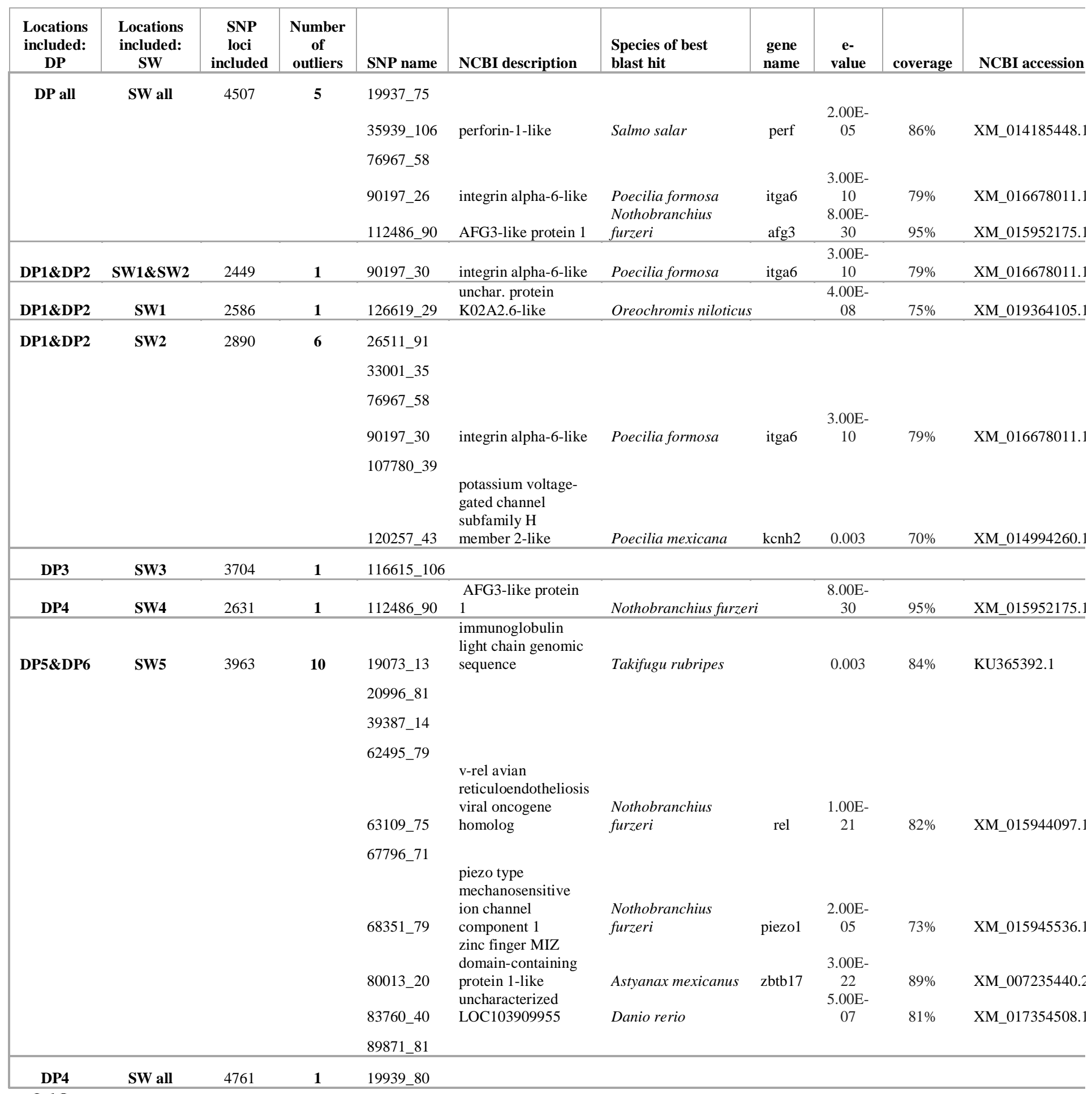

968 


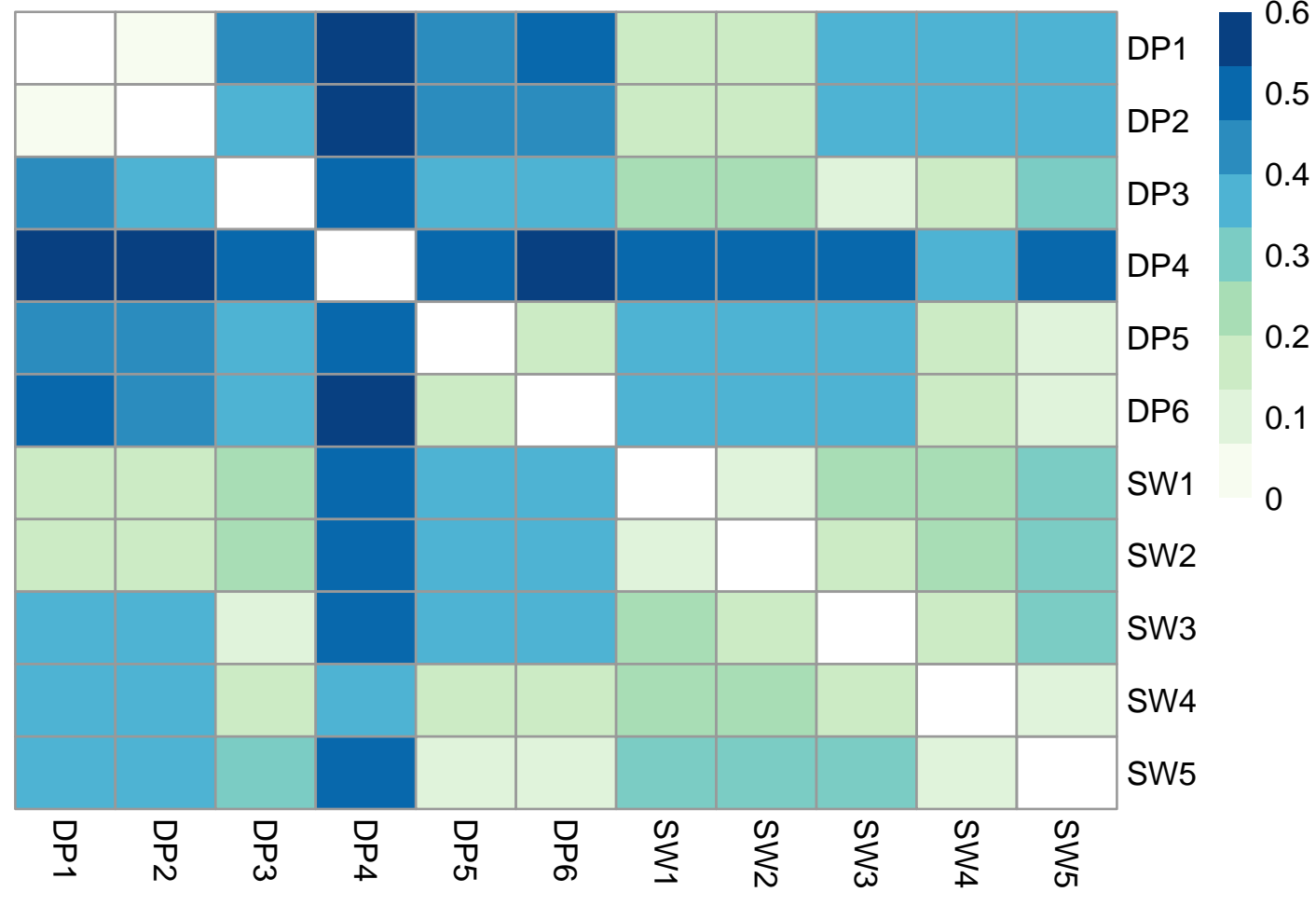




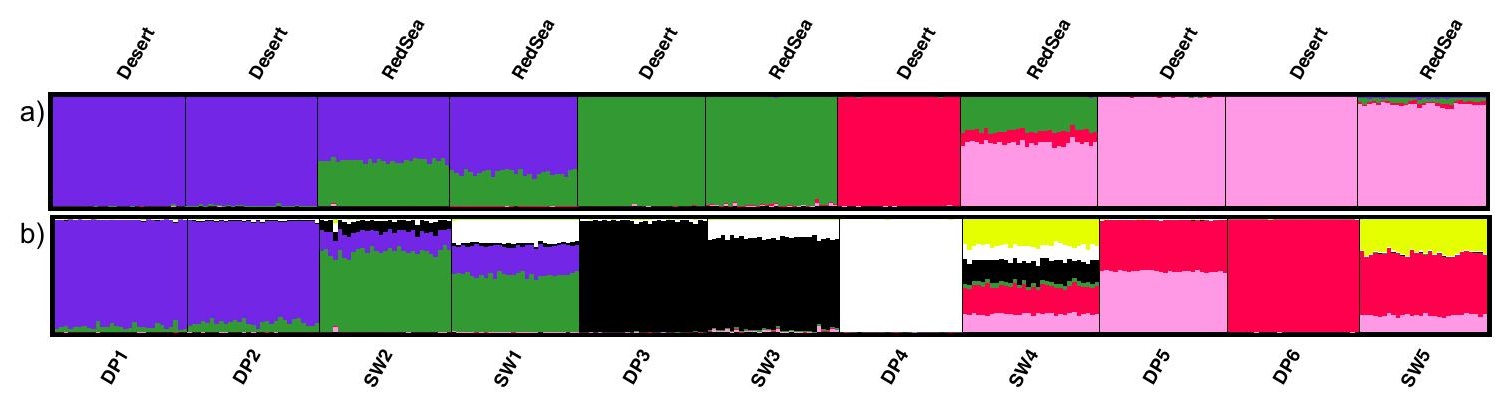


a)

b)

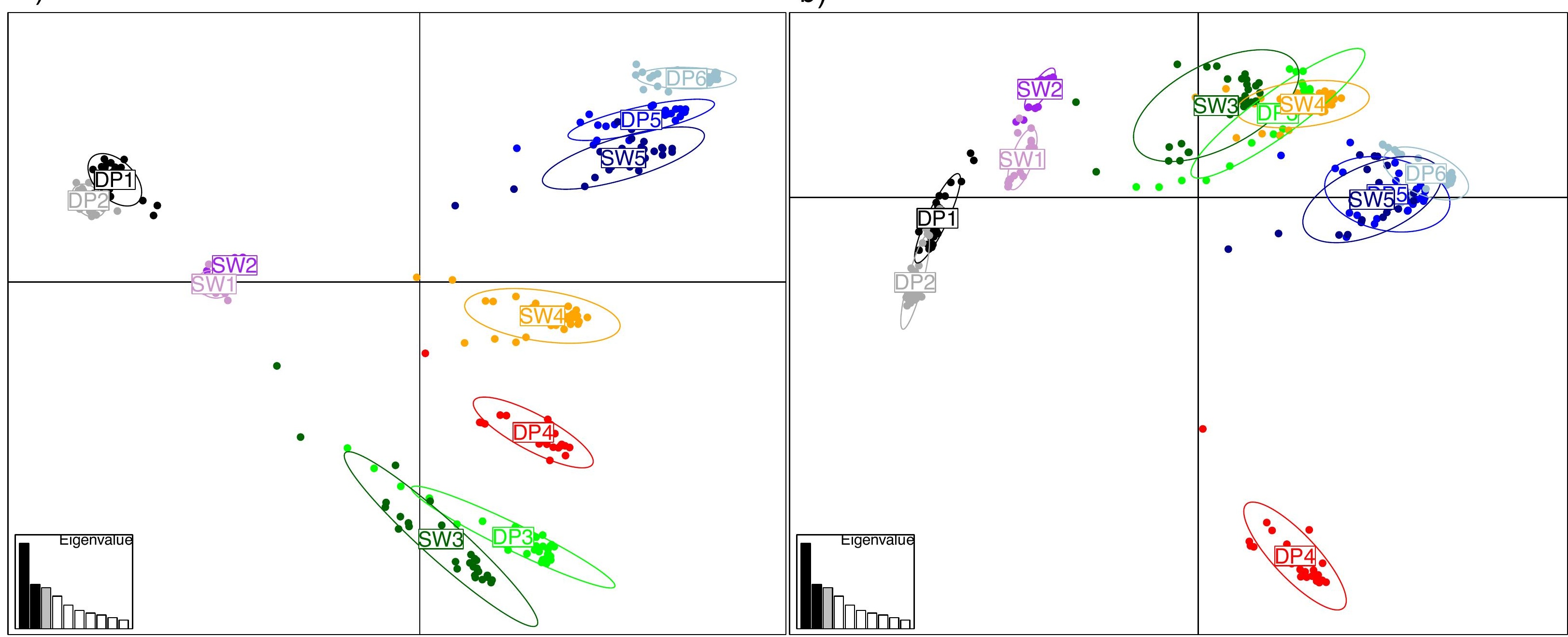




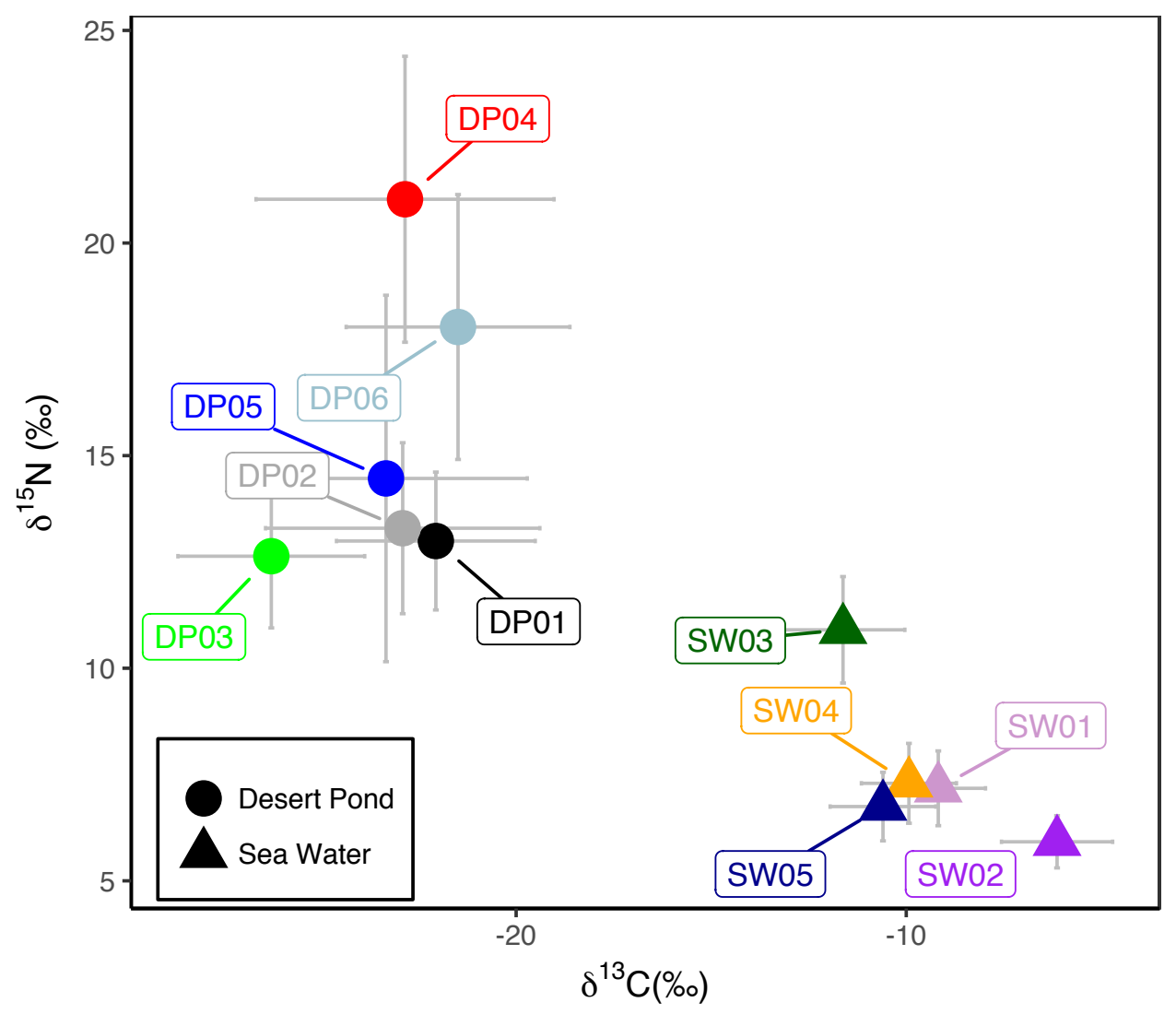


